\title{
МЕТАСТРУКТУРЫ. НОВЫЕ ПРИЕМЫ И ПРИНЦИПЫ В ФОРМООБРАЗОВАНИИ И ОРГАНИЗАЦИИ ФУНКЦИЙ
}

\author{
Болдырева Полина Сергеевна \\ МАРХИ
}

\begin{abstract}
Аннотация: Представленная статья дает обоснования для внедрения в будущем метаструктур в усложненную ткань города. Раскрываются основные понятия (метаструктура, метазвено, метасвязь) и степень изученности темы. Приводится классификация по 6 основным типологиям. Перечисляются примеры зарубежных и отечественных прогнозируемых метаструктур и существующих прототипов. Выделяются основные градостроительные принципы организации. Выдвигается предположение о необходимости создания метаструктур при пространственном прототипировании городов будущего.
\end{abstract}

Ключевые слова: Метаструктура, система, метазвено, метасвязь, саморегулирующаяся система, усложненность.

\section{METASTRUCTURES. NEW PRINCIPLES AND TECHIQUES IN SHAPING AND FUNCTIONAL ORGANIZATION}

\section{Boldyreva Polina Sergeevna}

\begin{abstract}
The abstract presence evidence for applying metastcuctures in the complicated system of the city in the future. The basic concepts (metastructure, meta-link, meta-communication) and the degree of knowledge of the topic are revealed. Classification of 6 main typologies are given. Foreign and native examples of predicted metastructures and existing prototypes are given. The main urban development principles of the organization are highlighted. An assumption is made about the need to create metastructures for spatial prototyping of cities of the future.
\end{abstract}

Key words: Metastructure, system, metalink, metacommunication, selfregulating system, complexity. 
Метаструктура - объект метаархитектуры; комплекс взаимосвязанных зданий, представляющих собой единую замкнутую саморегулирующуюся структуру с высокой функциональной гибкостью, возможностью объемнопространственного изменения с течением времени, наличием высококонцентрированных связей. Данным объектам свойственны мультимодальность, мультифункциональность, высокая степень автономности, разветвленность, наличие временных и постоянных составляющих, открытость для диалога с контекстом. Метаструктуры состоят из метазвеньев, соединенных метасвязями.

Метазвено - структурная единица метасистемы, представляющее собой одновременно целостное и дискретное ядро с набором нескольких функций, способное с течением времени менять как функциональную программу, так и объемно-пространственное решение.

Метасвязь - структурная единица метасистемы, осуществляющая связь, определяющая характер интеграции периферических частей метазвеньев друг с другом; метасвязь зависит от метазвеньев, ее набор функций (менее разветвленный, чем в метазвене) подстраивается под сценарии соединяемых частей, а следовательно, она также склонна к смене своих качественных и количественных характеристик.

В условиях стремительного роста мегаполисов, расширения их пространственных границ (территориальных и высотных), увеличения населения, усложнения типологий зданий, насыщения их бОльшим количеством функций и связей, появление такого нового типа систем зданий, как метаструктур, весьма вероятно в ближайшем будущем. Метаструктуры позволят минимизировать радиусы доступности, предоставить человеку в пределах одной саморегулирующийся и автономной системы зданий все необходимые функции, услуги.

Внедрение метаструктур в будущем даст много преимуществ при пространственном прототипировании городов. Основные преимущества: программная гибкость, адаптивность, способность изменяться с течением времени за счет наличия внутри одной системы, помимо постоянных составляющих, например жилых ячеек, временные, такие как производственные или общественные. Различные части метаструктуры при устаревании своей функции заменяются на иной “программный блок” с более актуальной программой, учитывающей потребности текущего времени. Таким 
образом, метаструктуры ликвидируют феномен существования неэффективно эксплуатируемых, заброшенных зданий и территорий в ткани города.

Одна из наиболее ярких концепций самодостаточных гиперконструкций, способных вместить в себя население целого города с собственной инфраструктурой, встречается в аркологии, архитектурном направлении 1960-70х гг. Примечательны работы ее основоположника, Паоло Солери (“Аркология: город в образе человека” (1969) - подробный обзор его гипотез и проектов). Основная идея трудов заключается в максимально эффективном использовании земной поверхности и компактном расселении людей внутри здания.

Интерес к теме спекулятивных мегасистем в 1960-х гг. также прослеживается в работах группы Archigram (Питер Кук, Уорен Чок, Рон Херрон, Дэнис Кромптон, Майкл Уэбб и Дэвид Грин). Ее представители мыслят уже в категориях не только пространства, но и времени, выдвигают концепцию «недетерминирующей архитектуры», последовательно отвергающей монументальность, образность, стабильную форму (наиболее ярко в проекте «Plug-in-city» - «Штепсельный город»).

В рамках спекулятивной архитектуры работает и современный урбанист, архитектор Лиам Янг. В его исследованиях анализируются сценарии будущего в городах и то, как на города влияют технологии; выдвигаются гипотезы и предположения, где в мегаполисах, изменённых процессами современности, могут появиться новые формы быта и коммуникации.

Современные взгляды на многозначность, структурность и значимость мегаполисов, как наиболее вероятных очагов возникновения новых моделей существования и их объемно-пространственных решений, изложены в трудах Яна Гейла и Эдварда Глейзера («Триумф города»).

Прогнозируемые метаструктуры и существующие прототипы можно классифицировать по 6 основным типологиям. Все метаструктуры, в первую очередь, различаются по размеру: XS $\left(100000 \mathrm{~m}^{2}\right)$, S $\left(200000 \mathrm{~m}^{2}\right), \mathrm{M}(400000$ $\left.\mathrm{M}^{2}\right)$, L (600000 м²), XL (1000000 м²), XXL (2000000 м²). По форме, общему объемно-пространственному решению, их можно разделить на вертикальные, горизонтальные и смешанные. По факторам формообразования выделяются естественные, искусственные (техногенные) и комбинированные, образованные под действием искусственных и естественных факторов. Также метаструктуры классифицируются по степени “гибкости”, изменяемости и 
возможности функционального роста, по количеству метазвеньев и по степени пространственной плотности.

В современной зарубежной практике можно выявить следующие группы примеров метаструктур:

- Утопические проекты метаархитектуры. Примеры: Hyperbuilding (бюро OMA), Plug-in-City (группа Archigram), Shimizu/Mega-city pyramid (архитектор Dante Bini), NOAH (архитектор Kevin Schopfer).

- Прототипы метаархитектурных звеньев. Примеры: Market hall (бюро MVRDV), Celosia (бюро MVRDV), Mirador (бюро MVRDV), Parkrand (бюро MVRDV), Linked Hybrid (архитектор Steven Holl).

В отечественной архитектурно-строительной практике можно выявить существующие неизменяемые прототипы метаструктур. Примеры: Главное здание МГУ (арх. Л.Руднев), Нефтяные камни в Азербайджане.

Выделяется 6 градостроительных принципов организации метаструктур. Принцип развитой транспортной обеспеченности подразумевает, что темп роста, развития, заполняемости метаструктур напрямую зависит от уровня активности места, его транспортной оснащенности. Транспорт обеспечивает циркуляцию потоков вне системы, соответственно влияет на нее извне, отражая при этом характер взаимодействия с окружением (мегаполисом/городом). Принцип ресурсной обеспеченности связан с геопотенциалом места, влияющем на вектор и темп развития, ставит промышленность как неотъемлемое постоянное звено структуры. По принципу формирования «драйвера развития», «точки притяжения», метаструктура проектируется как конгломерат (в условиях неосвоенной территории), способный явиться отправной точкой развития. Принцип дополнения/ соседства подразумевает формирование метаструктуры как системы, функционально обогащающей ткань мегаполиса или города. Примечателен и принцип паразитизма, когда метаструктура развивается на основе функционального потенциала, особенностей, объемнопространственного решения предшествующих блоков, постепенно (со временем) меняя их программу. Принцип устойчивого развития основан на энергетической автономности, поддерживающей непрерывный ход процессов, жизненный цикл.

Метаструктура может располагаться как в мегаполисе, так и в развивающемся городе или же на неосвоенной территории. Характер и степень интеграции данной системы, ее объемно-пространственное 
воплощение, степень заполняемости и изменяемости в выбранной среде зависит от функциональной схемы окружения, его особенностей и векторов специализации, потенциала места и перспектив развития как среды в целом, так и отдельно рассмотренных объектов, пешеходной и транспортной доступности, точек активности.

На сегодняшний день становятся все более очевидными высокие темпы глобализации, урбанизации, требующие более сложных типологий объектов. Устаревают модель ярусного расположения функций в зданиях, неизменяемая монофункциональность пространств, малая типологическая вариативность, связанная также и с ограниченностью конструктивных решений масштабных объектов. Но уже сейчас существуют прототипы метаструктур и проекты прогнозируемого будущего. Поэтому, весьма вероятно внедрение полноценных метаструктур в ткань города уже в ближайшее время.

\section{Приложение}

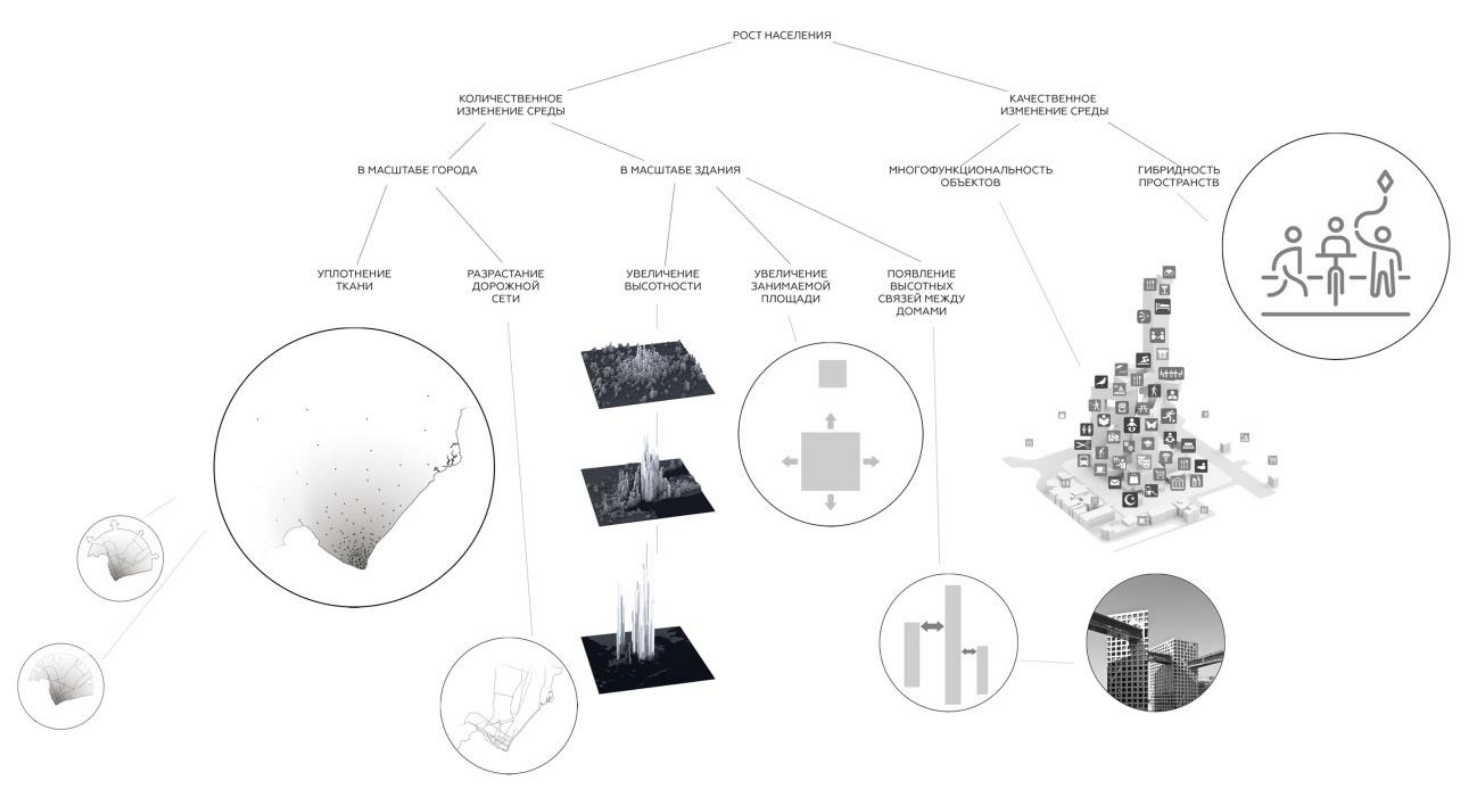

Рис. 1. Причины и предпосылки возникновения метаструктур 

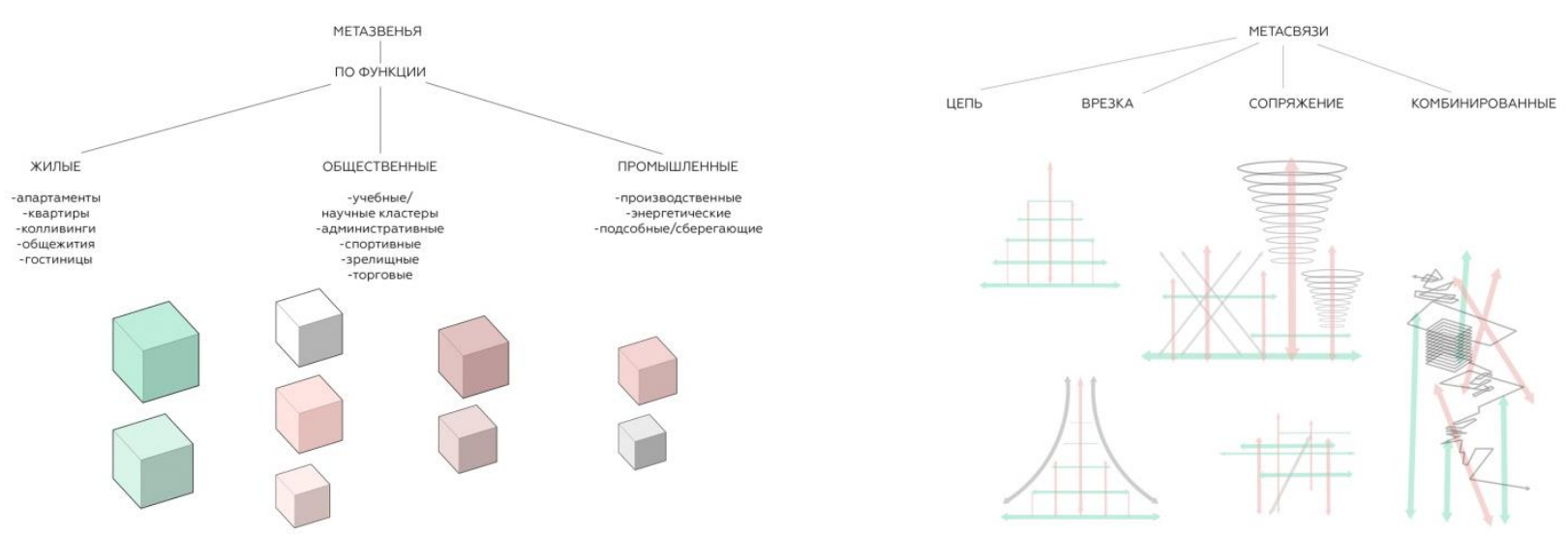

Рис. 2. Метазвенья. Метасвязи

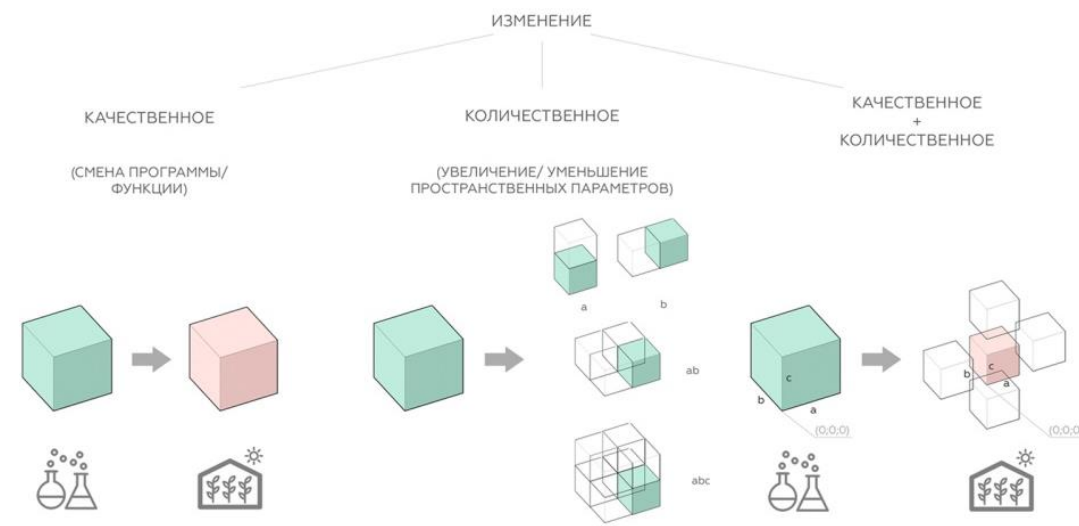

Рис. 3. Типы изменений 


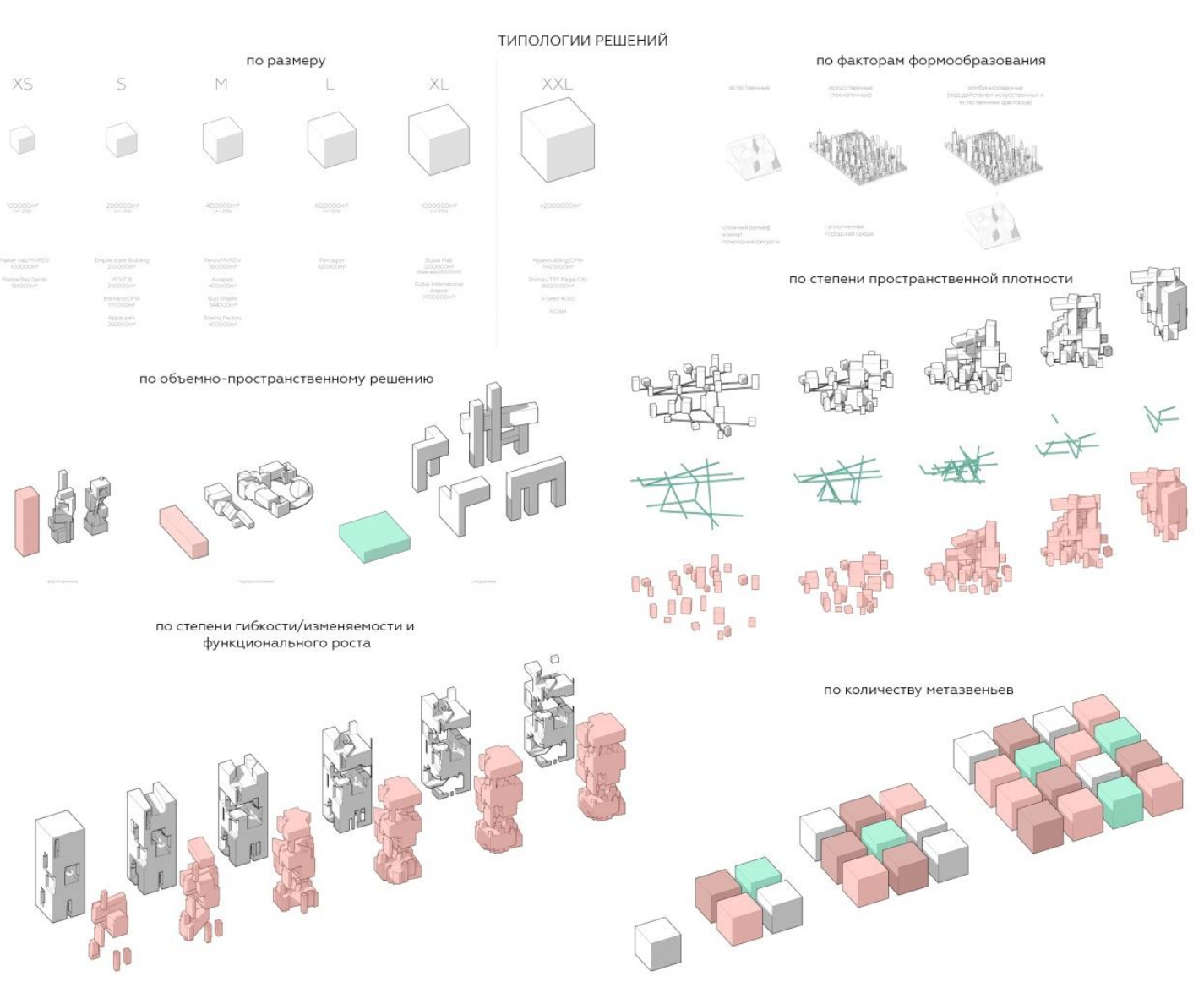

Рис. 4. Типология решений

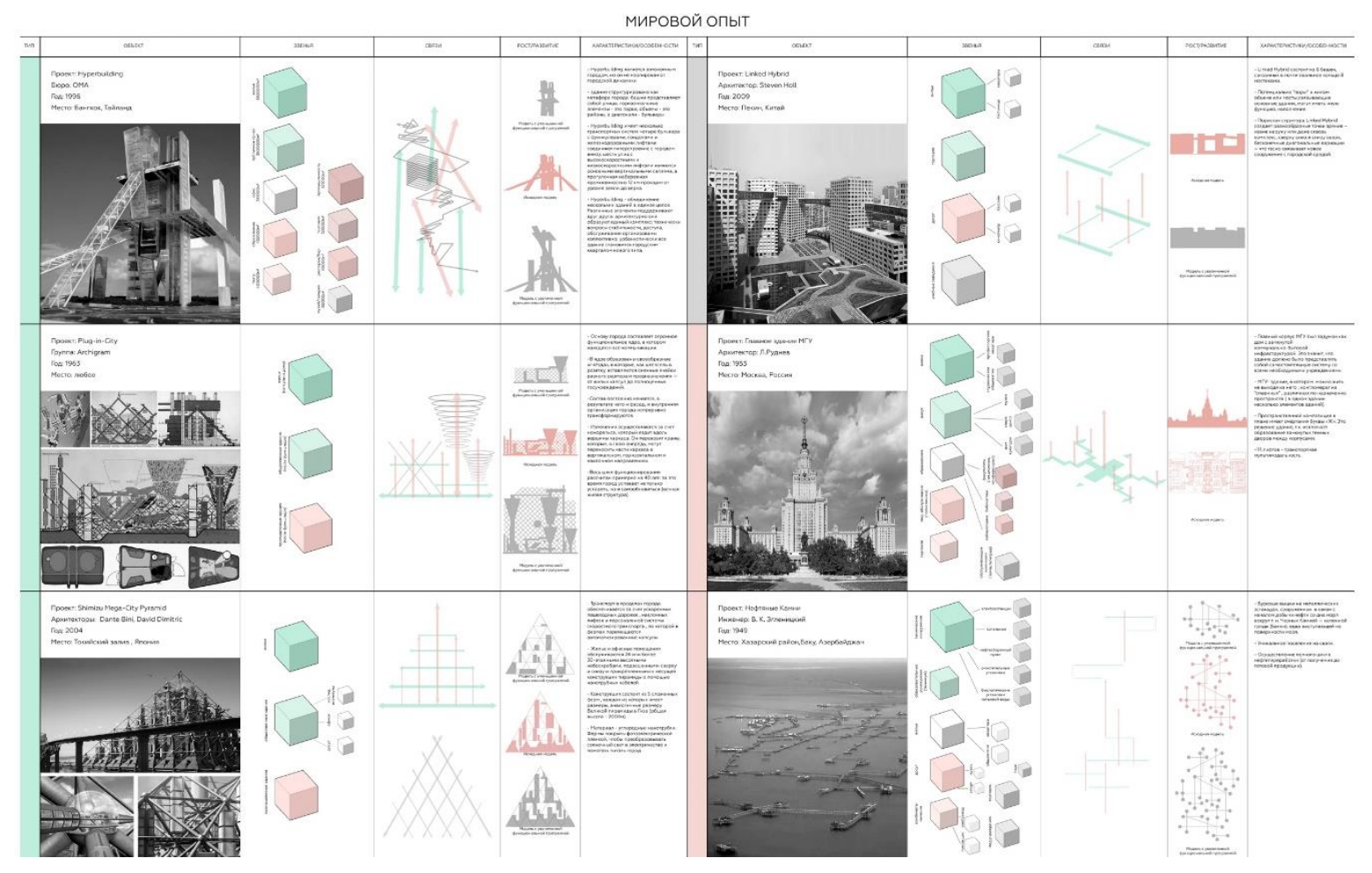

Рис. 5. Мировой опыт 


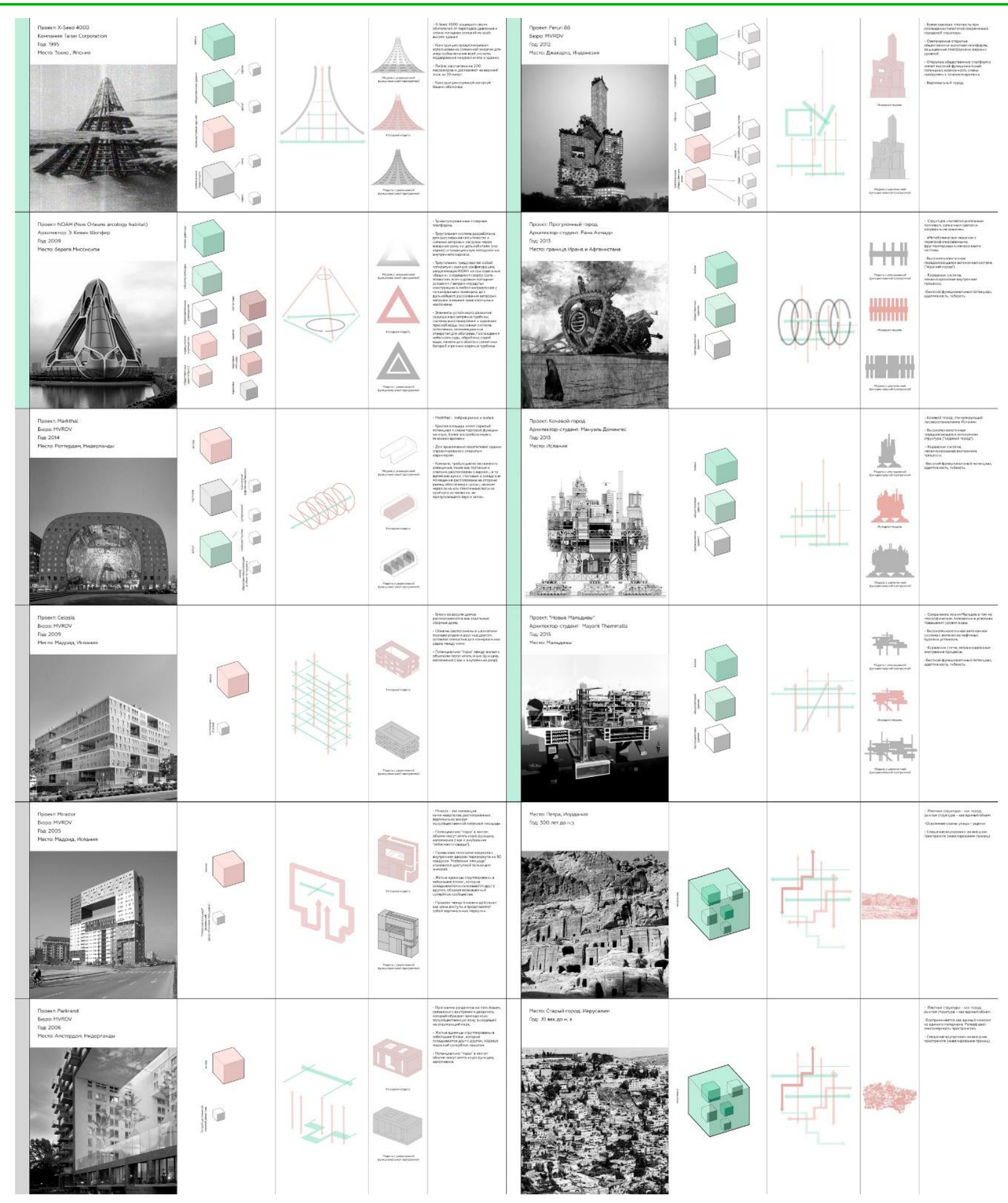

Рис. 6. Мировой опыт. Часть 2 


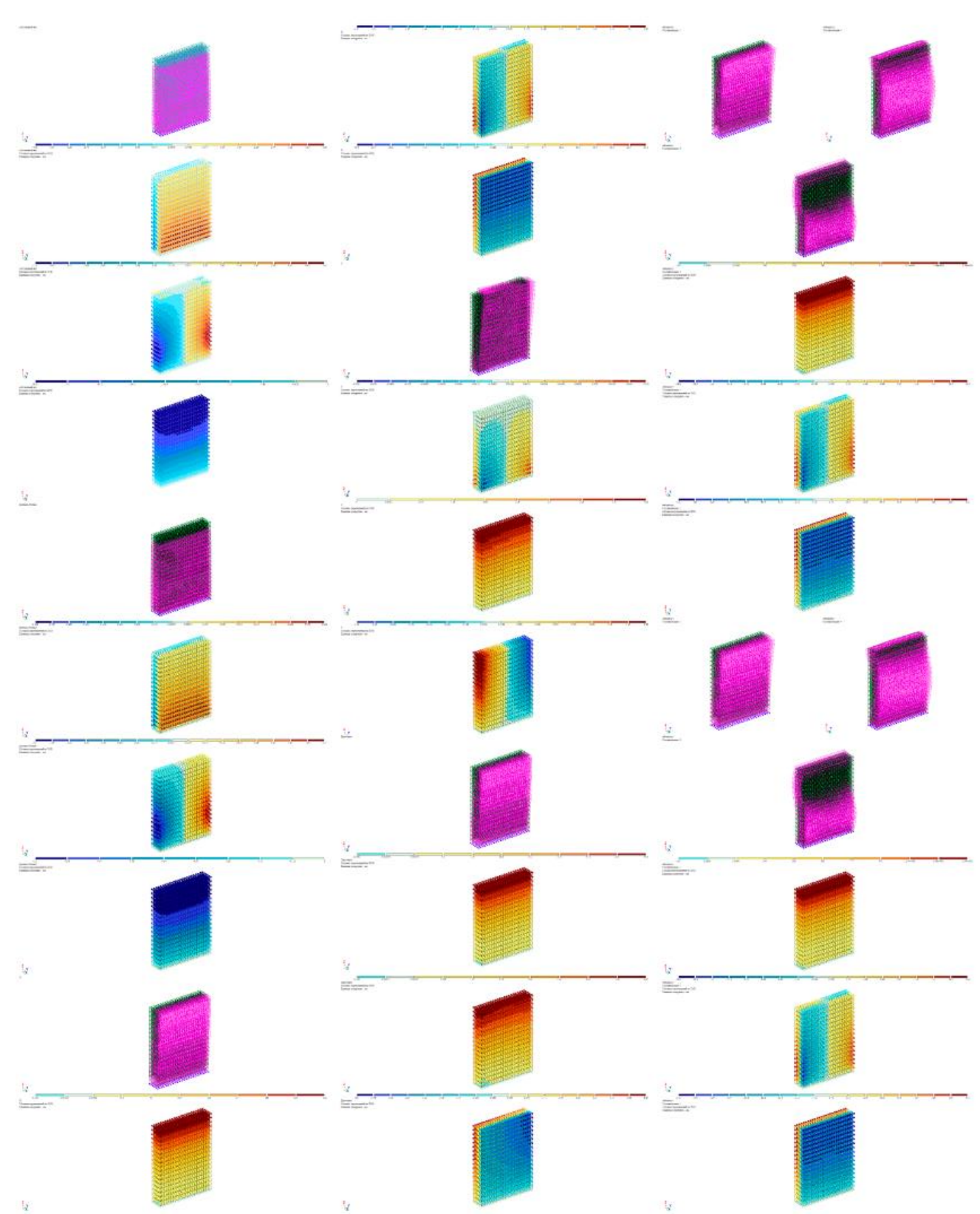

Рис. 7. Математическое моделирование конструкции. Мозаика перемещений (под действием статических и динамических нагрузок)

\section{Список литературы}

1. Paolo Soleri. Arcology : the city in the image of man - Cambridge, Mass. : MIT Press, 1973

2. Simon Sadler. Archigram: Architecture without Architecture- MIT Press, 2005 
3. Эдвард Глейзер: Триумф города. Как наше величайшее изобретение делает нас богаче, умнее, экологичнее, здоровее/ Пер. с англ. И.Кушнарева М.: Издательство Института Гайдара, 2014

4. Ян Гейл. Город для людей [Электронный ресурс] - 2012 .Режим доступа: https://rucont.ru/efd/256080

5. Ян Гейл. Жизнь среди зданий. - М.: Концерн „Крост“, 2012 